\title{
Advances, problems, and complications of polypectomy
}

This article was published in the following Dove Press journal:

Clinical and Experimental Gastroenterology

30 August 2014

Number of times this article has been viewed

\section{Andrea Anderloni \\ Manol Jovani \\ Cesare Hassan \\ Alessandro Repici}

Digestive Endoscopy Unit, Division of Gastroenterology, Humanitas Research Hospital, Rozzano, Milan, Italy
Correspondence: Alessandro Repici Digestive Endoscopy Unit, Division of Gastroenterology, Humanitas Research Hospital, Rozzano, Milan, Italy

Tel +3902 82242579

Fax +390282242292

Email alessandro.repici@humanitas.it
Abstract: The major role of colonoscopy with polypectomy in reducing the incidence of and mortality from colorectal cancer has been firmly established. Yet there is cause to be uneasy. One of the most striking recent findings is that there is an alarmingly high incomplete polyp removal rate. This phenomenon, together with missed polyps during screening colonoscopy, is thought to be responsible for the majority of interval cancers. Knowledge of serrated polyps needs to broaden as well, since they are quite often missed or incompletely removed. Removal of small and diminutive polyps is almost devoid of complications. Cold snare polypectomy seems to be the best approach for these lesions, with biopsy forcep removal reserved only for the tiniest of polyps. Hot snare or hot biopsy forcep removal of these lesions is no longer recommended. Endoscopic mucosal resection and endoscopic submucosal dissection have proven to be effective in the removal of large colorectal lesions, avoiding surgery in the majority of patients, with acceptably low complication rates. Variants of these approaches, as well as new hybrid techniques, are being currently tested. In this paper, we review the current status of the different approaches in removing polypoid and nonpolypoid lesions of the colon, their complications, and future directions in the prevention of colorectal cancer.

Keywords: cold snare polypectomy, serrated polyps, endoscopic resection, submucosal, mucosal, colonoscopy, adenoma, colorectal cancer, bleeding, perforation

\section{Introduction}

Endoscopic polypectomy consists of the excision of a colonic polyp in the course of colonoscopy and is routinely performed in most centers in Western countries today. It was proposed in the early seventies as a nonsurgical way of dealing with precancerous conditions of the colon. ${ }^{1}$ In more recent decades, endoscopic polypectomy has witnessed continuous advances because of improvements in the technology of colonoscopes and accessories, as well as in endoscopic techniques. Endoscopists can now perform relatively simple procedures, such as removal of small polyps by biopsy forcep or snares, as well as endoscopic mucosal resections (EMR) and endoscopic submucosal resections (ESD) for large polyps or early-stage colorectal cancer, hence reducing the need for surgical intervention. ${ }^{2-7}$

The importance of polypectomy derives from the fact that it interferes with the natural history of colorectal cancer. ${ }^{8,9}$ Polyps have been classified as diminutive ( $\leq 5 \mathrm{~mm}$ ), small $(6-9 \mathrm{~mm})$, large $(\geq 10 \mathrm{~mm})$, and gigantic $(>30 \mathrm{~mm}),{ }^{10}$ and their potential for advanced neoplasia is size-dependent. ${ }^{11}$ A recent systematic review found that the overall rate of advanced adenomas in patients undergoing screening colonoscopy is $5.6 \%$, with higher probability of harboring advanced adenomas in larger polyps 
$(0.9 \%$ in patients with diminutive polyps, $1.7 \%$ in subcentimeter polyps, and $73.5 \%$ in large polyps). ${ }^{12}$ However, some recent studies have found higher rates of advanced neoplasia, in the order of $9 \%-10 \%$, even in diminutive and small polyps. ${ }^{13,14}$ This emphasizes the importance of population-based screening for detecting and removing even small polyps. ${ }^{15}$ Polyp and adenoma detection rates (ADR) are considered the most important markers of quality in colonoscopy, since a strong correlation between ADR and risk of colorectal cancer has been observed. ${ }^{15,16}$ Colonoscopy with polypectomy is protective against colorectal cancer, although to a lesser degree for the right colon. ${ }^{17}$ The rate of interval cancers, that is colorectal cancer diagnosed within 5 years from a negative colonoscopy, is indirectly proportional to the quality of the index colonoscopy. ${ }^{16,18,19}$ It has been estimated that missed polyps at this colonoscopy account for the majority of such cases $(50 \%-80 \%)$, followed by incomplete removal of precancerous lesions (15\%-30\%) and occurrence of new aggressive neoplasia in genetically susceptible patients in the rest. ${ }^{18,20}$

Serrated polyps need to be sought after carefully, because they are considered important precursors to interval colorectal cancer. ${ }^{20,21}$ They are little known by endoscopists, are more challenging to visualize because of subtle endoscopic features, and their margins are difficult to delineate, resulting in higher rates of missed or incomplete polyp removal when compared with traditional polyps. ${ }^{22}$ In one recent study, nearly half of such lesions were incompletely excised. ${ }^{20}$ All this underscores the need for high-quality colonoscopy, both for the detection of polyps/adenomas and for their effective and complete removal. ${ }^{23}$

Many factors account for a low-quality diagnostic colonoscopy with low ADR, such as quality of bowel preparation and operator experience. Much effort has been put into increasing the ADR in diagnostic colonoscopy, such as high-definition white light endoscopy, optical zoom functions, retrograde viewing devices, chromoendoscopy, dye-based and virtual or electronic chromoendoscopy, such as narrow-band imaging, flexible spectral imaging color enhancement, and I-Scan, as well as autofluorescence and confocal laser microscopy. ${ }^{24-28}$ On the other hand, less effort and attention has been given to evaluating complete polypectomy. Some direct information on the adequacy of polyp resection rates has become available only recently, ${ }^{20,29}$ and specific criteria for quality assessment are being developed..$^{30}$ The consequence of such a lack of information has been a wide variety of approaches to polypectomy over time, especially for polyps smaller than $10 \mathrm{~mm},{ }^{30,31}$ resulting in suboptimal polypectomy rates..$^{20,29}$
Efforts to increase the rates of complete polypectomy include improvement of technology, ${ }^{32}$ development of virtual and hands-on training courses, ${ }^{33}$ and objective criteria for quality assessment in polypectomy. ${ }^{30}$

These shortcomings notwithstanding, colonoscopy with polypectomy has been very useful in reducing the incidence and mortality from colorectal cancer in the past decades, and will be the backbone of prevention of this cancer in the future. In this paper, we will briefly review the advances in polypectomy, as well as its problems and complications. (See Table 1).

\section{Diminutive and small polyps General principles}

The vast majority (over $80 \%-90 \%$ ) of polyps encountered during routine colonoscopy are diminutive $(\leq 5 \mathrm{~mm})$ or small (6-9 mm), ${ }^{15,34}$ so questions regarding their removal have very important clinical consequences. However, until now, little data have existed on the optimal polypectomy technique for such polyps, resulting in a wide variety of polypectomy techniques among endoscopists. In a survey of US endoscopists, $50 \%$ used forceps (hot or cold) for $1-3 \mathrm{~mm}$ polyps and electrosurgical snare for 7-9 $\mathrm{mm}$ polyps, with no preferred method for polyps $4-6 \mathrm{~mm}$ in size. ${ }^{31}$

\section{Forcep biopsy polypectomy}

Cold forcep biopsy polypectomy is quick, easy to apply, and cheap. Unfortunately, this technique is associated with significant rates of incomplete polyp removal and hence with increased polyp recurrence rates and consequent risk of interval colorectal cancer. ${ }^{35}$ The reason might be that bleeding after the first bite can obscure the visual field and hide the rest of the residual polyp, rendering it difficult to remove. In a landmark study by Efthymiou et al, ${ }^{29}$ EMR was performed at the site of an apparently complete forcep-based polypectomy, and showed that even under the "ideal" conditions of

Table I Introduction section, key points

- Screening colonoscopy with polypectomy has significantly reduced the incidence of, and mortality from, colorectal cancer.

- Polyp and adenoma detection rates are the most important markers of quality in diagnostic colonoscopy.

- Incomplete polyp resection is one of the major causes of interval cancer.

- The advanced-neoplasia potential of colonic polyps is size-dependent.

- Serrated polyps need to be carefully sought after, since they are frequently misdiagnosed and incompletely removed, and hence significantly contribute to the development of interval CRC.

- New platforms in both diagnostic and therapeutic colonoscopy are being developed. 
a prospective study, overall only $39 \%$ of diminutive polyps were completely removed. Histology was the only predictor of complete polypectomy, with adenomatous polyps being more likely to be removed than hyperplastic ones $(62 \%$ and $24 \%$, respectively). Successive studies have similarly found complete removal rates of only $51 \%-79 \%$ for adenomatous polyps with biopsy forceps. ${ }^{36,37}$ Therefore, it seems that cold biopsy forcep removal of small and diminutive polyps is not an optimal choice, except for tiny polyps of 1-2 mm that can be resected in a single bite. ${ }^{2,29}$ This technique may also be preferable in cases of polyps found at difficult sites of the colon, since forceps are more easily maneuvered than snares. ${ }^{36}$

Proposed alternatives to conventional biopsy forceps include the use of larger cold biopsy forceps, such as jumbo forceps, or hot polypectomy. One study compared the efficacy of jumbo biopsy forceps with conventional ones for the removal of polyps $<6 \mathrm{~mm}$ in one bite. ${ }^{36}$ Even although jumbo forceps showed a significantly higher visually complete removal rate $(78.8 \%$ versus $50.7 \% ; P<0.001)$ and shorter performance time, the rate of complete eradication was not significantly different between the two types of forceps. Hot biopsy forcep removal was once popular, ${ }^{31}$ because it was thought that the addition of electrocautery to the biopsy bite would serve to burn the surrounding tissue and thus enhance the rate of complete polyp excision, inducing simultaneous hemostasis. This method has fallen out of favor ${ }^{2}$ because of the increased complication rates and poor quality of the biological material obtained, while maintaining the same polyp eradication rate as cold biopsy forceps. ${ }^{38,39}$

\section{Snare polypectomy}

Cold snare polypectomy is an easy-to-apply technique that has become a favorite for small and diminutive polyps. Techniques have been described in detail elsewhere. ${ }^{2}$ Briefly, the endoscopist advances the snare sheath, opens the snare and encircles the polyp. The snare is then slowly and progressively closed, with the aim of capturing 1-2 mm of normal tissue around the polyp, until complete closure is achieved and the polyp is guillotined. The polyp can then be suctioned and retrieved for histologic assessment.

In a recent comparative study, cold snare polypectomy was shown to be significantly superior to biopsy forcep removal in terms of histologic eradication rate $(93.2 \%$ versus $75.9 \%, P=0.009$ ) and procedure-related time. ${ }^{37}$ This was specifically evident for polyps $>4 \mathrm{~mm}$, while no significant difference was observed for smaller polyps. Snare resection was more expensive and associated with a lower retrieval rate compared with biopsy forcep retrieval, but this did not reach statistical significance.

Three studies have compared cold snare polypectomy with hot snare polypectomy for small and diminutive polyps. ${ }^{40-42}$ No significant difference in terms of polyp removal rates and retrieval was observed between the two methods. Intraprocedural bleeding was more frequent in the cold group in two studies, ${ }^{40,41}$ but resolved spontaneously and required no additional intervention, while in the other, ${ }^{42}$ immediate and delayed bleeding was more frequently observed in the hot snare group. Hot snare polypectomy required a longer procedural time and had more postprocedural abdominal symptoms. All three studies concluded that cold snare resection was superior to hot snare polypectomy and hence should be the first choice for resection of small and diminutive polyps. However, pedunculated polyps may benefit more from hot snare polypectomy. ${ }^{2}$

\section{Polyp retrieval}

Most studies do not see snare resection as increasing the rate of failed polyp retrieval..$^{37,40,41}$ Yet, in a recent, large, retrospective study, small polyps (particularly diminutive polyps, $<5 \mathrm{~mm}$ ), sessile morphology, right colon location, and cold snare polypectomy were factors influencing polyp retrieval. ${ }^{11}$

It has been argued that polyp retrieval may not even be necessary for diminutive polyps. ${ }^{43}$ The American Society for Gastrointestinal Endoscopy has in fact recently released a statement in which two in vivo paradigms were defined. ${ }^{44}$ The first is called the "resect and discard" strategy, according to which if the real-time histologic assessment of a diminutive polyp is performed endoscopically with high confidence, pathologic assessment becomes unnecessary. The second is called the "discard" or "leave-in" strategy, according to which all diminutive polyps in the rectosigmoid that appear hyperplastic at endoscopy, with high confidence, should not be resected or sampled, but left in situ. ${ }^{44}$ These statements are based on epidemiologic data showing a very low prevalence of advanced histology in diminutive polyps and a high prevalence of hyperplastic lesions in the rectosigmoid in the screening setting ${ }^{12,45}$ and on studies demonstrating that in vivo polyp histology assessment is now adequately accurate. ${ }^{28,46}$ Cost analyses have found that the "resect and discard" and "leave-in" paradigms are associated with significant cost and time savings, with almost no increase in patient cancer risk. ${ }^{47}$ It is still unclear whether these policies could be applied to serrated lesions as well. ${ }^{43}$ However, some caution is warranted since these statements work upon the assumption of complete 
polyp resection, an assumption which is not always true, ${ }^{20,29,37}$ and also some studies have reported higher advanced histology rates for small and diminutive polyps. ${ }^{13,14}$

As previously observed, incomplete polyp removal is responsible for up to one third of all interval cancers. Even in the "ideal" setting of a recently reported prospective study, an alarming incomplete resection rate of $10 \%-60 \%$ was reported for small and diminutive polyps. Higher rates might reasonably be suspected in general clinical practice. ${ }^{20,29}$ Forceps removal has repeatedly been reported as an independent risk factor for incomplete polyp eradication and hence increased recurrence rates. ${ }^{20,21,29,37}$ Increased polyp size,${ }^{20,37}$ serrated adenomas, ${ }^{20,21}$ and colonoscopist's experience ${ }^{20}$ have been reported as additional risk factors for incomplete resection. These factors need to be carefully considered when performing polypectomy, in order to reduce the rates of incomplete removal and hence interval cancer.

In sum, cold snare polypectomy seems the best option for small and diminutive polyps. Increased effort should be made to increase the rate of complete polyp resection, both by increasing awareness of the incomplete polypectomy phenomenon and by improving resection techniques and accessories. (See Table 2).

\section{Large colonic polyps or lesions General principles}

Endoscopic management of large $(\geq 10 \mathrm{~mm})$ colorectal lesions is more complex. The Paris classification has been widely used for morphologic assessment of such lesions, and distinguishes between protruded or polypoid lesions (0-I), either sessile (0-Is), pedunculated (0-Ip) or semipedunculated (0-Isp), excavated lesions ( $0-$ III) and nonprotruding, nonexcavated, or nonpolypoid lesions (0-II), and either slightly elevated (0-IIa), flat (0-IIb), slightly depressed (0-IIc), or their combination (0-Iia + IIc or 0-Iic + IIa). Large 0-IIa lesions $(\geq 10 \mathrm{~mm})$ are also called lateral spreading tumors

Table 2 Diminutive and small polyps section, key points

- The vast majority of colonic polyps are diminutive $(\leq 5 \mathrm{~mm})$ or small (6-9 mm).

- Polypectomy by cold forceps biopsy is associated with high rates of incomplete removal in this setting. Polypectomy by hot forceps must be avoided, as it is associated with high complication rates.

- Cold snare polypectomy is superior to biopsy forceps in terms of complete polyp removal. It has similar complete removal rates as hot snare polypectomy, but with less complications.

- The "resect and discard" and "leave-in" policies for diminutive polyps are slowly entering clinical practice.
(LST) and are divided into granular LST and nongranular LST types, based on their surface appearance. ${ }^{48,49}$ Real-time in vivo microscopic characterization by visualization of the pitt pattern and vascular pattern is also a crucial step in the overall evaluation of colorectal lesions. ${ }^{50-53}$ High accuracy in evaluating the depth of colorectal lesions was recently reported with through-the-scope miniprobe ultrasound devices. ${ }^{54}$ More studies will be necessary to establish the role and utility of ultrasound in this setting.

Surgery has historically been the mainstay of treatment for large colorectal polyps and lesions. However, such treatment is plagued by high complication and morbidity rates, as well as high costs. ${ }^{55,56}$ EMR and ESD have been shown to be valid alternatives to surgery in the majority of cases in this setting, with lower complication rates and costs. ${ }^{3,757}$

Meticulous evaluation of both macroscopic and microscopic appearance of a lesion is mandatory since it dictates indications and type of treatment choice. ${ }^{58}$ For example, nonpolypoid lesions have a greater risk of harboring cancer than polypoid lesions, irrespective of size; nongranular LST lesions have generally higher rates of submucosal invasion than granular LST-type lesions, and in this last group, lesions with even-sized nodules have a lower rate of submucosal invasion than lesions with mixed-sized nodules. ${ }^{49,58}$ These factors influence not only the decision between surgical or endoscopic excision, but also the type of endoscopic treatment (standard polypectomy, EMR, or ESD). ${ }^{4,7}$ Microscopic evaluation, particularly by the application of narrow-band imaging, also gives relevant information that helps to estimate in vivo histology (hyperplastic, adenomatous, superficial, or deep invading cancer), determining thus whether a lesion is amenable to endoscopic resection (lesion extended only to the mucosa or $<1,000 \mu \mathrm{m}$ into the submucosal layer) or not. ${ }^{51-53,59}$ Of course, in cases where the appearance of a lesion strongly suggests deep invasion, such as pitt pattern $\mathrm{V}$ or excavated lesions (0-III), surgery should be considered. ${ }^{3,4,57,60}$

\section{EMR and ESD techniques}

The plane of resection during EMR/ESD is in the superficial or medium submucosal layer, making these techniques different from traditional polypectomy, the resection plane of which is at the mucosal level. Both make use of submucosal injection of normal saline solution (with or without epinephrine), hypertonic solutions (glycerol), or colloid-based solutions (hydroxyethyl starch or succinylated gelatin) followed by stiff snare resection. ${ }^{3,4}$ If the mucosa does not lift (the "non-lift sign"), this can be considered an indirect sign of invasion and 
hence a contraindication to endoscopic removal. However, other factors may induce a similar reaction, such as fibrotic tissue from previous attempts at resection or cauterization, India ink tattooing, or ulceration. ${ }^{61}$

The "inject-and-cut" technique, with dynamic submucosal injection for creation of a protective cushion, is the most common EMR technique. It has been described in detail elsewhere. ${ }^{3,4}$ Briefly, after puncturing the submucosal layer, the injectant is infused while the needle is moved. Afterwards, if the lesion is $20 \mathrm{~mm}$ or less, it is captured as a whole with a stiff snare. The snare is then lifted from the wall, slightly loosened in order to release possible entrapped muscularis propria, and then strangled and transected using blended current. If, on the other hand, the lesion is larger, it can be resected piecemeal (in more pieces) in a similar fashion. After the first resection, the free margins of the lesion serve as an anchor point for successive resections, until the whole lesion is snared off. The different pieces are then retrieved for histological assessment.

Different ESD techniques exist and have been described in detail elsewhere. ${ }^{3,4}$ Briefly, a first submucosal injection is performed at the proximal borders of the lesion. A hemicircumferential incision is applied at the edges, after which the submucosal layer is directly dissected with a variety of endoscopic knives, at this half circumference. The same process is then applied on the other side of the lesion, until the whole lesion is resected en bloc. Another technique, the ESD universal, is somewhat different. In this case, a circumferential incision is performed at the edges of the lesion and a partial dissection is made at the base of the lesion. This is then followed by either en bloc snare resection of the freed lesion or completion of the circumferential dissection toward the center until the whole lesion is resected en bloc.

\section{Endoscopic mucosal resection}

EMR is usually employed for lesions up to $20 \mathrm{~mm}$, because with this technique the preferable en bloc removal of larger lesions is difficult. ${ }^{4}$ Of course, piecemeal resection of larger lesions is feasible with EMR. Swan et al reported a success rate of $95 \%$ when removing difficult sessile polyps larger than $20 \mathrm{~mm}$ by piecemeal EMR, avoiding surgery in $90 \%$ of cases, with significant reduction in morbidity and complication rates, as well as costs. ${ }^{56}$ Similarly, effective piecemeal removal of $90 \%-96 \%$ of colonic lesions larger than $20 \mathrm{~mm}$ in single or multiple endoscopic sessions, and avoidance of surgery in more than $85 \%$ of patients with significant cost savings has been reported in two recent studies. ${ }^{57,62}$ EMR, both en bloc and piecemeal, has also been successfully used for early colorectal cancer, particularly when limited to the mucosa, ${ }^{63,64}$ and for defiant polyps, ie, those that cannot be resected by standard snare polypectomy techniques. ${ }^{65}$ Overall, in expert hands, EMR can result in successful treatment of most colonic lesions, with nearly half removed en bloc and the rest piecemeal, and only $3 \%-10 \%$ of patients needing surgery. ${ }^{66,67}$

However, a mean adenoma recurrence rate of $25 \%$ $(0.8 \%-50 \%)$ has been reported in the literature after piecemeal EMR for large $(>20 \mathrm{~mm})$ or gigantic $(>30 \mathrm{~mm})$ lesions. ${ }^{10,17,56,57,68,69}$ Reported predictors of recurrence after effective EMR include lesions larger than $40 \mathrm{~mm},{ }^{57,67}$ need for use of argon plasma coagulation, and piecemeal resection in six or more pieces. ${ }^{57}$ The first follow-up endoscopy is usually performed 3-6 months after the EMR procedure since most adenoma recurrences are already visible by this time ${ }^{70,71}$ "Late" recurrence of adenoma, defined as detection of adenoma after a first negative control colonoscopy, is a relatively rare phenomenon, found in $4 \%$ of patients. A normal-appearing scar with negative biopsies at first control endoscopy is predictive of long-term eradication. ${ }^{10}$ Some of the attempts to reduce the rate of recurrence after EMR include application of argon plasma coagulation to the borders or microscopic bridges of residual tissue in the resected areas, ${ }^{70}$ and the use of alternative hybrid EMR techniques, such as circumferential precutting for lesions larger than $30 \mathrm{~mm}$ and successive en bloc removal. ${ }^{72}$ However, adenoma recurrences are minor, benign, and easily treated endoscopically. ${ }^{56,57,65,69,73}$

As previously mentioned, EMR can also be ineffective in resecting or curing large lesions. Factors independently associated with failed or incomplete resection include previous attempts at resection, location at the proximal colon or ileocecal valve, piecemeal resection, 0-IIa + c morphology, nongranular LST, pitt pattern V, or submucosal carcinoma. ${ }^{57,64}$ The major factors associated with incomplete cure include depressed (type 0 -III) lesions, since they are frequently associated with deep submucosal infiltration. ${ }^{49,64}$ Adding the technique of endoscopic mucosal ablation (application of high-power argon plasma coagulation after creation of a submucosal fluid cushion) to EMR, has recently been proposed as rescue therapy in cases of previously incomplete piecemeal EMR or adenoma recurrence. ${ }^{74}$

Lift-and-cut resection is the most frequently used EMR technique. Other types of EMR techniques include capassisted EMR, EMR with band ligation, and underwater EMR. Cap-assisted EMR and EMR with band ligation should be considered only for rectal lesions, because of the high risk of perforation in other areas of the colon. ${ }^{75,76}$ Underwater EMR 
is a novel piecemeal resection technique, ${ }^{77}$ that makes no use of submucosal injection. Reports of a first pilot study show that underwater EMR is safe and effective, with a low delayed bleeding rate $(4.8 \%)$ and no perforation. No early (1-year) recurrence of adenomatous tissue has been observed. ${ }^{77}$ This technique is easy to learn and seems a valid alternative to traditional EMR and ESD. ${ }^{78}$ As previously mentioned, piecemeal EMR resection is associated with relatively high rates of local recurrence. One additional caveat of piecemeal resection is suboptimal pathologic evaluation of the resected specimen. In fact, en bloc resection is preferable for an adequate histologic assessment, since both horizontal and deep margins can be evaluated, and if found negative, a diagnosis of complete resection can be formulated. Other features of curative resection include submucosal invasion $<1,000 \mu \mathrm{m}$, no lymphatic or vascular involvement, and no poorly differentiated components. ${ }^{60}$ Piecemeal excision yields fragmentary pieces, making these assessments very difficult, if not impossible. ${ }^{79}$

\section{Endoscopic submucosal resection}

ESD is a newly introduced, technically difficult, and timeconsuming technique, but is effective in overcoming the shortcomings of EMR. ${ }^{64,79}$ ESD is mainly performed in Japan, although it is slowly expanding to the West as well. . $^{6,80,81}$ Even though there are no standardized indications for ESD, it is usually performed to treat difficult lesions larger than $20 \mathrm{~mm}$, nongranular LST, or type V pitt pattern, when highgrade dysplasia/cancer or superficial submucosal invasion is suspected, when other endoscopic techniques have failed or are deemed ineffective for en bloc removal, in colorectal carcinoid lesions, and in sporadic localized tumors in ulcerative colitis. ${ }^{81,82}$ A recent systematic review and meta-analysis of 22 studies including a total of 2,774 patients showed that ESD is highly effective in the management of lesions $\geq 20 \mathrm{~mm}$ as well as post-EMR recurrences, with an $\mathrm{R} 0$ resection rate of $88 \%$ and virtually null risk of post-R0 ESD recurrence. ${ }^{6}$ This same review found that Asian studies had a higher $\mathrm{R} 0$ resection rate than European series ( $88 \%$ versus $65 \%, P=0.03$ ), which probably reflects the cultural and technical differences between these two groups.

\section{EMR versus ESD}

Two studies have compared ESD with EMR for the management of large colorectal lesions. ${ }^{7,73}$ The first ${ }^{73}$ is a large retrospective study which found that, overall, ESD has higher en bloc ( $84 \%$ versus $33 \%, P<0.0001$ ) and curative resection rates, with lower recurrences $(2 \%$ versus $14 \%, P<0.0001)$ compared with EMR. These results came at the price of a longer procedural time and a tendency towards higher perforation rates for ESD. The lower recurrence rates in the ESD group were related to higher en bloc resection rates, since recurrence rates of $13 \%$, similar to piecemeal EMR, were observed in cases when ESD did not achieve en bloc resection. In the case of EMR too, piecemeal resection was associated with higher recurrence rates when compared with en bloc resection $(20 \%$ versus 3\%). However, both methods resulted in similar rates of colon preservation. ${ }^{73}$ The second one, ${ }^{7}$ a recent, large, multicenter, prospective, observational study, confirmed that overall rates of en bloc resection were higher with $\mathrm{ESD}$ (94.5\% versus $56.9 \%, P<0.01$ ), especially for larger lesions ( $\geq 40 \mathrm{~mm}$ ). For larger lesions, the tendency was to choose ESD over EMR, especially for flat and mixed-type lesions.

\section{Other cases}

EMR/ESD can be safely performed with good results even for lesions in difficult locations of the colon, ${ }^{4}$ such as close to the dentate line, ${ }^{83}$ ileocecal valve, ${ }^{57,60}$ or appendiceal orifice, ${ }^{84}$ while lesions that extend through the valve into the ileum or appendix should be referred for surgery. ${ }^{5}$ Large pedunculated polyps on the other hand can be resected by traditional hot snare loop polypectomy techniques at one third to one half the distance from the base of the polyp. ${ }^{4}$ Deep endoscopic resection of large, difficult colon polyps and with full-thickness closure of the resected site under laparoscopic observation by the use of tissue apposition systems are novel treatment options which are being currently investigated. ${ }^{85}$ Combined laparoscopic-endoscopic techniques have been recently introduced for resection of difficult large colonic lesions in selected cases. ${ }^{86,87}$ Other hybrid and full-thickness techniques are currently being evaluated in animal models. ${ }^{88,89}$ These developments are paralleled by a rapid evolution in therapeutic devices and accessories as well. (See Table 3). ${ }^{32}$

Table 3 Large colonic polyps or lesions section, key points

- Meticulous evaluation of the morphology (Paris classification), pittpattern (Kudo classification) and vascular pattern (NICE classification) dictates indications and type of treatment choice for large ( $\geq 10 \mathrm{~mm})$ colorectal lesions.

- Endoscopic mucosal resection is effective in removing en-bloc lesions of 10-20 mm, and piecemeal lesions $>20 \mathrm{~mm}$, avoiding surgery in over $90 \%$ of patients. Piecemeal resection is associated with high adenoma recurrence rates ( $25 \%$ of cases), easily treated with other endoscopic mucosal resection sessions.

- Endoscopic submucosal resection is technically demanding, but has high en-bloc removal and low recurrence, rates ( $\geq 90 \%$ and $\leq 2 \%$ respectively).

- Endoscopic mucosal resection and endoscopic submucosal resection have an overall similar colon-preserving efficacy. 


\section{Complications \\ General principles}

Even though colonoscopy with or without polypectomy is considered on the whole safe, it is not entirely free of risks. It can be associated with complications, such as bleeding, perforation, and post-polypectomy syndrome. Most of these complications are self-limiting or can be readily managed conservatively and/or endoscopically. More rarely, they can be life-threatening and/or require surgery. ${ }^{90}$

Diagnostic colonoscopy has an extremely low rate of complications, and virtually all complications are related to interventional colonoscopy, particularly polypectomy. ${ }^{90-93}$ The majority of complications in this setting has been imputed to electrocautery. ${ }^{2,90}$ All procedures dealing with removal of large polyps (conventional polypectomy, EMR, ESD, or their variants) include electrocautery. Submucosal injection for creating a protective cushion is usually performed with the aim of reducing iatrogenic thermal injury in these cases ${ }^{94}$ even though this may not always be necessary. ${ }^{77}$ However, electrocautery should be avoided for the removal of small and diminutive polyps, with the possible exception of pedunculated polyps. ${ }^{2}$ In fact, in times when hot forcep and/or hot snare polypectomy were popular in this setting, ${ }^{31}$ unacceptably high complication rates, mainly perforations and delayed bleeding, were observed. ${ }^{2,95}$ The unanimous conclusion of most recent studies is that cold polypectomy in this setting, either by forceps or snare, is safe, with virtually no major complications. . $^{13,36,37,40-42,52,96}$ This should hence be the standard for safe and qualitative polypectomy for small and diminutive polyps. Some of the risk factors for complications in this setting include multiple polypectomies, increased size, right colon location, ${ }^{96}$ an inexperienced endoscopist, and older age. ${ }^{93}$

Up to one third of patients report mild gastrointestinal symptoms after colonoscopy with polypectomy, including abdominal pain, bloating, diarrhea, and nausea, which usually resolve within 24-48 hours. Other complications, much rarer, but potentially more dangerous, include splenic hematoma or rupture, acute appendicitis, diverticulitis, incarcerated hernias, intramural hematoma, bacteremia, and colonic explosion..$^{90}$

\section{Bleeding}

Bleeding, either immediate (during polypectomy) or delayed (usually within 1 week, but possible in up to 3-4 weeks), is the most frequently observed complication..$^{2,90}$

\section{Small and diminutive polyps}

For small and diminutive polyps, the immediate bleeding rate has been reported to be in the order of $0.5 \%-2.2 \%$, while delayed bleeding is rarer, in the order of $0.3 \%-$ $0.6 \%{ }^{13,95-99}$ Most of the bleeding observed in this setting is either self-limiting or easily treated in the same endoscopic session, with clip placement or adrenaline injection. ${ }^{13,96}$ Some of the proposed methods of preventing bleeding, such as prophylactic use of hemostatic clips ${ }^{100}$ or prophylactic argon plasma coagulation, on the polypectomy scar ${ }^{101}$ do not seem to be useful for preventing delayed bleeding in this setting.

Most studies, ${ }^{37,95,96}$ although not all, ${ }^{13}$ do not consider antiplatelet agents, such as aspirin and nonsteroidal antiinflammatory drugs, a risk factor for bleeding in this setting, and hence international guidelines do not recommend their routine discontinuation before colonoscopy or removal of small and diminutive polyps. ${ }^{102}$ Clopidogrel, on the other hand, seems to be associated with higher post-polypectomy bleeding rates. ${ }^{103}$ Anticoagulation therapy has also been previously reported in retrospective or case-control studies as being a risk factor for bleeding in diagnostic and therapeutic colonoscopy, ${ }^{95,99,104}$ and as such its suspension before endoscopy is recommended by practice guidelines. ${ }^{102}$ However, a recent, prospective, randomized controlled study has concluded that continuation of anticoagulation therapy does not significantly increase the risk of bleeding after cold snare removal of small and diminutive polyps, ${ }^{42}$ and hence its discontinuation may not be necessary in this setting, especially in patients with high risk of thrombosis. In this scenario, polyp size has been consistently reported as an independent predictor of bleeding, ${ }^{13,96-99}$ while conflicting data exist regarding location in the right colon..$^{95,98}$

\section{Large lesions}

EMR/ESD have roughly similar reported intraprocedural and delayed bleeding rates, ranging from $1 \%$ to $10 \%$ in different studies. ${ }^{7,57,67,73,82,105} \mathrm{~A}$ recent systematic review and meta-analysis found an overall bleeding rate of $2 \%$ for ESD, with all cases being successfully managed endoscopically. ${ }^{6}$ Increased size, ${ }^{106}$ right colon location, ${ }^{56,98,105,106}$ and aspirin consumption, ${ }^{105}$ have been reported as risk factors for delayed bleeding in this setting. Piecemeal resection and previous attempts at resection are not considered risk factors for delayed bleeding, ${ }^{105}$ whilst clip placement after EMR seemed to be a protective factor in a recent retrospective study. ${ }^{106}$

Pedunculated polyps are fed by multiple vessels and therefore have an increased risk of bleeding. Epinephrine injection to both the stalk and the polyp head, ${ }^{107}$ as well as looping ${ }^{108}$ and clipping ${ }^{67}$ techniques, have been deployed 
successfully to reduce the risk of bleeding after hot snare polypectomy. Even though injection of epinephrine may only prevent immediate but not delayed bleeding, ${ }^{109}$ this is the most widely used preventive method, and many authors prefer reserving other techniques only for high-risk patients. ${ }^{5}$ Some of the reported factors predisposing patients with large pedunculated polyps to a increased risk of bleeding include older age, type of current used, size and histology of polyps, stalk diameter, and use of anticlotting drugs. ${ }^{108,109}$

\section{Perforation}

Perforation (immediate or delayed) is the second most common complication of polypectomy. ${ }^{2,3}$ For small and diminutive polyps, the risk of perforation is practically nil when cold polypectomy is performed. ${ }^{13,36,37}$ Perforation in polypectomy has in fact been mostly associated with electrocautery, ${ }^{110}$ so this technique is no longer advisable. ${ }^{2}$

On the other hand, removal of large lesions with EMR/ ESD is, as expected, associated with higher perforation rates. Of the two methods, EMR is safer, with reported perforation rates ranging between $0 \%$ and $1.5 \%$. ${ }^{7,56,57,77,80} \mathrm{~A}$ recent systematic review found an overall perforation rate of nearly $4 \%$ after an ESD procedure, ${ }^{6}$ with rates ranging from $1.5 \%$ to $10 \%$ in the literature..$^{7,82,111,112}$ Lack of experience is a major risk factor for perforation during an ESD procedure. Different authors have observed that the rate of complications in general, and perforations specifically, decreases with increasing experience, as well as improvement of devices and techniques. ${ }^{7,80}$ Lesions larger than $50 \mathrm{~mm}^{7,80}$ and nongranular LST morphology ${ }^{113}$ are two other important risk factors for perforation in ESD. Location at the proximal colon, especially the cecum, are also risk factors for perforation, since the colonic wall is thin, whilst rectal location is a protective factor against perforation since the wall is thicker and retroperitoneal. ${ }^{105}$ Recently, a risk stratification scoring system showed good predictability for both success and complication rates after EMR for lesions larger than $20 \mathrm{~mm} .{ }^{62}$ Future studies will be needed to validate this score. Most of the perforations observed with EMR/ESD can be successfully treated endoscopically with clip placement, and only a minority of patients require surgery. ${ }^{7,13,57}$ Use of over-the-scope clip ${ }^{114}$ and endoscopic suturing devices ${ }^{115}$ are recently introduced techniques for endoscopic management of ESD-related perforations, and need to be further validated.

\section{Post-polypectomy coagulation syndrome}

Post-polypectomy coagulation syndrome is a rare manifestation of peritoneal irritation because of electrocautery but
Table 4 Complications section, key points

- Diagnostic colonoscopy is extremely safe. Complications arise mostly from polypectomy with electrocautery.

- Bleeding is the most frequent complication of polyp removal $(0.3-2 \%$ for diminutive and small polyps; $1-10 \%$ for endoscopic mucosal resection/endoscopic submucosal resection). In most cases, it is managed endoscopically. Risk factors include increased size and right colon location. Antiplatelet, or even anticoagulation agents do not seem to be risk factors for bleeding in small and diminutive polyps, whilst they are considered such for large polyps.

- Perforation is the second most common complication $(0 \%$ for small and diminutive polyps if electrocautery is avoided; $0-1.5 \%$ for endoscopic mucosal resection and $1.5-10 \%$ for endoscopic submucosal resection in large polyps). Most cases can be managed endoscopically. Risk factors include lack of experience, larger size and right colon location.

- Post-polypectomy coagulation syndrome is rare ( $1-4 \%$ of cases; but only $0.07 \%$ require hospitalization). It is easily managed conservatively.

without evidence of perforation on computed tomography scan. It occurs in $1.35 \%-3.7 \%$ of patients undergoing excision of large lesions, ${ }^{67,68,106}$ but requires hospitalization in only $0.07 \% .{ }^{116}$ It is characterized by fever, abdominal pain, and increased inflammation markers (C-reactive protein and leukocyte count). Post-polypectomy coagulation syndrome has an excellent prognosis and is managed conservatively with medical therapy. ${ }^{116}$

\section{Death and stricture formation}

Reported polypectomy-related mortality, even for advanced procedures such as EMR/ESD, is almost nil. ${ }^{2-7} \mathrm{ESD} / \mathrm{EMR}$ for very large lesions may rarely induce stricturing. Post-ESD/ EMR endoscopic tissue transplantation or decellularized biological scaffold placement may prevent such occurrence and is currently being tested in animal studies. ${ }^{117}$ In brief, removal of small and diminutive polyps is extremely safe, while removal of larger lesions is associated with acceptably low complication rates. This is especially significant when considering that patients very often avoid surgical intervention and the related morbidity and mortality, as well as costs. (See Table 4).

\section{Surveillance after polypectomy}

As previously observed, polyps that are missed or incompletely removed during index colonoscopy contribute to the development of interval colorectal cancer. This underscores the pivotal need for adequate surveillance policies. Two of the principal guidelines that impact worldwide clinical practice are those published by the European Society of Gastrointestinal Endoscopy (ESGE) ${ }^{118}$ and the United States Multi-Society Task Force (MSTF). ${ }^{119}$ Both guidelines stratify 
patients according to the findings of the index colonoscopy. The recommendations are essentially as follows:

- if no polyps or adenomas are found, or in cases of only distal small hyperplastic polyps, control colonoscopy should be performed after 10 years (MSTF)

- if low-risk adenomas (LRA; 1-2 tubular adenomas, $<10 \mathrm{~mm}$, low-grade dysplasia) are found, control colonoscopy should be performed after 10 years (ESGE) or 5-10 years (MSTF)

- if high-risk adenomas (HRA; three or more adenomas or $\geq 10 \mathrm{~mm}$, villous histology, or high-grade dysplasia) are found, control colonoscopy should be performed after 3 years (ESGE, MSTF); in the event of piecemeal removal of large lesions, control endoscopy may be considered in less than 1 year (MSTF) or at 6 months (ESGE)

- if more than ten adenomas are found, this is considered a HRA group, hence control endoscopy should be performed in less than 3 years (MSFT) and the patient should be referred for genetic counseling (ESGE)

- for sessile serrated polyps, if $<10 \mathrm{~mm}$ and no dysplasia, control endoscopy should be performed at 5 years (MSTF) or 10 years (ESGE); if $\geq 10 \mathrm{~mm}$ or dysplastic, control endoscopy should be performed at 3 years (ESGE, MSTF); if serrated polyposis syndrome, control should be performed at 1 year (MSTF) and the patient should be referred for genetic counseling (ESGE).

Thereafter, surveillance recommendations depend on the findings at first surveillance colonoscopy. The recommendations can be summarized as follows:

- if LRA were detected at index colonoscopy, and first surveillance colonoscopy is negative, control endoscopy should be performed at 10 years (MSTF)

- if LRA were detected at index colonoscopy and at first surveillance, control endoscopy should be performed at 5 years (MSTF) or 10 years (ESGE)

- if LRA were detected at index colonoscopy and HRA detected at first surveillance, control endoscopy should be performed in 3 years (MSTF)

- if HRA were detected at index colonoscopy and first surveillance colonoscopy is negative, control endoscopy should be performed in 5 years (ESGE, MSTF)

- if HRA were detected at index colonoscopy and LRA at first surveillance, control endoscopy should be performed in 5 years (MSTF)

- if HRA were detected at index colonoscopy and HRA is detected at first surveillance, control endoscopy should be performed in 3 years (ESGE, MSTF).
Both guidelines advise against the use of interval fecal occult blood tests, and both recognize that these recommendations should be adapted to each clinical scenario presented to the physician. Finally, recommendations from both guidelines work under the assumption that a high-quality colonoscopy with complete removal of all neoplastic tissue occurred at baseline. If, on the other hand, there is a poor quality index colonoscopy, the intervals between controls should be reduced.

\section{Conclusion}

Over the last decades, colonoscopy with polypectomy has shown remarkable success in preventing colorectal cancer. Cold snare polypectomy seems the best option for small and diminutive polyps, while hot biopsy forcep removal should be abandoned. Relatively high rates of missed polyps and incomplete polyp resection rates are the two most important problems of which the endoscopists should be aware today. Endoscopic removal of large colonic lesions either by EMR, $\mathrm{ESD}$, or one of their variants, is now feasible, with high success rates and acceptably low complications, reducing the need for surgery. Therefore, it should be considered the first choice in this setting, whenever feasible. Future efforts should concentrate on developing didactic programs, endoscopic instruments, and accessories aimed at improving quality of colonoscopy with regard to both ADR, macroscopic and in vivo microscopic evaluation, as well as complete excision rates for both small and large colonic lesions. EMR and ESD procedures are still technically difficult. Improvement of already existing techniques and development of novel advanced resection techniques hold promise for expanding the boundaries of endoscopic resection in the near future beyond the current limits. Prevention of colorectal cancer and reduction in the need for surgery is an already present reality, which needs to be further implemented.

\section{Disclosure}

The authors report no conflicts of interest in this work.

\section{References}

1. Wolff WI, Shinya H. A new approach to colonic polyps. Ann Surg. 1973;178(3):367-378.

2. Hewett DG. Colonoscopic polypectomy: current techniques and controversies. Gastroenterol Clin North Am. 2013;42(3):443-458.

3. Kaltenbach T, Soetikno R. Endoscopic resection of large colon polyps. Gastrointest Endosc Clin N Am. 2013;23(1):137-152.

4. Sanchez-Yague A, Kaltenbach T, Raju G, Soetikno R. Advanced endoscopic resection of colorectal lesions. Gastroenterol Clin North Am. 2013;42(3):459-477.

5. Tolliver KA, Rex DK. Colonoscopic polypectomy. Gastroenterol Clin North Am. 2008;37(1):229-251, ix. 
6. Repici A, Hassan C, De Paula Pessoa D, et al. Efficacy and safety of endoscopic submucosal dissection for colorectal neoplasia: a systematic review. Endoscopy. 2012;44(2):137-150.

7. Nakajima T, Saito Y, Tanaka S, et al. Current status of endoscopic resection strategy for large, early colorectal neoplasia in Japan. Surg Endosc. 2013;27(9):3262-3270.

8. Zauber AG, Winawer SJ, O’Brien MJ, et al. Colonoscopic polypectomy and long-term prevention of colorectal-cancer deaths. $N$ Engl J Med. 2012;366(8):687-696.

9. Shaukat A, Mongin SJ, Geisser MS, et al. Long-term mortality after screening for colorectal cancer. $N$ Engl J Med. 2013;369(12): 1106-1114.

10. Khashab M, Eid E, Rusche M, Rex DK. Incidence and predictors of "late" recurrences after endoscopic piecemeal resection of large sessile adenomas. Gastrointest Endosc. 2009;70(2):344-349.

11. Komeda Y, Suzuki N, Sarah M, et al. Factors associated with failed polyp retrieval at screening colonoscopy. Gastrointest Endosc. 2013;77(3):395-400.

12. Hassan C, Pickhardt PJ, Kim DH, et al. Systematic review: distribution of advanced neoplasia according to polyp size at screening colonoscopy. Aliment Pharmacol Ther. 2010;31(2):210-217.

13. Repici A, Hassan C, Vitetta E, et al. Safety of cold polypectomy for $<10 \mathrm{~mm}$ polyps at colonoscopy: a prospective multicenter study. Endoscopy. 2012;44(1):27-31.

14. Tsai FC, Strum WB. Prevalence of advanced adenomas in small and diminutive colon polyps using direct measurement of size. Dig Dis Sci. 2011;56(8):2384-2388.

15. von Karsa L, Patnick J, Segnan N. European guidelines for quality assurance in colorectal cancer screening and diagnosis. First Edition executive summary. Endoscopy. 2012;44 Suppl 3:SE1-SE8.

16. Kaminski MF, Regula J, Kraszewska E, et al. Quality indicators for colonoscopy and the risk of interval cancer. $N$ Engl J Med. 2010;362(19):1795-1803.

17. Singh H, Nugent Z, Demers AA, Kliewer EV, Mahmud SM, Bernstein $\mathrm{CN}$. The reduction in colorectal cancer mortality after colonoscopy varies by site of the cancer. Gastroenterology. 2010; 139(4):1128-1137.

18. Baxter NN, Sutradhar R, Forbes SS, Paszat LF, Saskin R, Rabeneck L. Analysis of administrative data finds endoscopist quality measures associated with postcolonoscopy colorectal cancer. Gastroenterology. 2011;140(1):65-72.

19. Robertson DJ, Lieberman DA, Winawer SJ, et al. Colorectal cancers soon after colonoscopy: a pooled multicohort analysis. Gut. 2014;63(6):949-956.

20. Pohl H, Srivastava A, Bensen SP, et al. Incomplete polyp resection during colonoscopy-results of the complete adenoma resection (CARE) study. Gastroenterology. 2013;144(1):74-80. e1.

21. Hetzel JT, Huang CS, Coukos JA, et al. Variation in the detection of serrated polyps in an average risk colorectal cancer screening cohort. Am J Gastroenterol. 2010;105(12):2656-2664.

22. Rex DK, Ahnen DJ, Baron JA, et al. Serrated lesions of the colorectum: review and recommendations from an expert panel. Am J Gastroenterol. 2012;107(9):1315-1329.

23. Rembacken B, Hassan C, Riemann JF, et al. Quality in screening colonoscopy: position statement of the European Society of Gastrointestinal Endoscopy (ESGE). Endoscopy. 2012;44(10):957-968.

24. Aihara $\mathrm{H}$, Saito $\mathrm{S}$, Inomata $\mathrm{H}$, et al. Computer-aided diagnosis of neoplastic colorectal lesions using 'real-time' numerical color analysis during autofluorescence endoscopy. Eur J Gastroenterol Hepatol. 2013;25(4):488-494.

25. Kiesslich R, Burg J, Vieth M, et al. Confocal laser endoscopy for diagnosing intraepithelial neoplasias and colorectal cancer in vivo. Gastroenterology. 2004;127(3):706-713.

26. DeMarco DC, Odstrcil E, Lara LF, et al. Impact of experience with a retrograde-viewing device on adenoma detection rates and withdrawal times during colonoscopy: the Third Eye Retroscope study group. Gastrointest Endosc. 2010;71(3):542-550.
27. Basford PJ, Longcroft-Wheaton G, Higgins B, Bhandari P. Highdefinition endoscopy with i-Scan for evaluation of small colon polyps: the HiSCOPE study. Gastrointest Endosc. 2014;79(1):111-118.

28. Rex DK. Narrow-band imaging without optical magnification for histologic analysis of colorectal polyps. Gastroenterology. 2009;136(4): 1174-1181.

29. Efthymiou M, Taylor ACF, Desmond PV, Allen PB, Chen RY. Biopsy forceps is inadequate for the resection of diminutive polyps. Endoscopy. 2011;43(4):312-316.

30. Gupta S, Bassett P, Man R, Suzuki N, Vance ME, Thomas-Gibson S. Validation of a novel method for assessing competency in polypectomy. Gastrointest Endosc. 2012;75(3):568-575.

31. Singh N, Harrison M, Rex DK. A survey of colonoscopic polypectomy practices among clinical gastroenterologists. Gastrointest Endosc. 2004;60(3):414-418.

32. Saxena P, Khashab MA. New platforms and devices in colonoscopy. Gastroenterol Clin North Am. 2013;42(3):671-688.

33. Ansell J, Hurley JJ, Horwood J, et al. The Welsh Institute for Minimal Access Therapy colonoscopy suitcase has construct and concurrent validity for colonoscopic polypectomy skills training: a prospective, cross-sectional study. Gastrointest Endosc. 2014;79(3):490-497.

34. Regula J, Rupinski M, Kraszewska E, et al. Colonoscopy in colorectalcancer screening for detection of advanced neoplasia. $N$ Engl J Med. 2006;355(18):1863-1872

35. Liu S, Ho SB, Krinsky ML. Quality of polyp resection during colonoscopy: are we achieving polyp clearance? Dig Dis Sci. 2012;57(7): 1786-1791.

36. Draganov PV, Chang MN, Alkhasawneh A, et al. Randomized, controlled trial of standard, large-capacity versus jumbo biopsy forceps for polypectomy of small, sessile, colorectal polyps. Gastrointest Endosc. 2012;75(1):118-126.

37. Lee CK, Shim J-J, Jang JY. Cold snare polypectomy vs cold forceps polypectomy using double-biopsy technique for removal of diminutive colorectal polyps: a prospective randomized study. Am J Gastroenterol. 2013;108(10):1593-1600.

38. Peluso F, Goldner F. Follow-up of hot biopsy forceps treatment of diminutive colonic polyps. Gastrointest Endosc. 1991;37(6):604-606.

39. Monkemuller KE, Fry LC, Jones BH, Wells C, Mikolaenko I, Eloubeidi M. Histological quality of polyps resected using the cold versus hot biopsy technique. Endoscopy. 2004;36(5):432-436.

40. Paspatis GA, Tribonias G, Konstantinidis K, et al. A prospective randomized comparison of cold vs hot snare polypectomy in the occurrence of postpolypectomy bleeding in small colonic polyps. Colorectal Dis. 2011;13(10):e345-e348.

41. Ichise Y, Horiuchi A, Nakayama Y, Tanaka N. Prospective randomized comparison of cold snare polypectomy and conventional polypectomy for small colorectal polyps. Digestion. 2011;84(1):78-81.

42. Horiuchi A, Nakayama Y, Kajiyama M, Tanaka N, Sano K, Graham DY. Removal of small colorectal polyps in anticoagulated patients: a prospective randomized comparison of cold snare and conventional polypectomy. Gastrointest Endosc. 2014;79(3):417-423.

43. Hassan C, Repici A, Zullo A, Kanakadandi V, Sharma P. Colonic polyps: are we ready to resect and discard? Gastrointest Endosc Clin NAm. 2013;23(3):663-678.

44. Rex DK, Kahi C, O’Brien M, et al. The American Society for Gastrointestinal Endoscopy PIVI (Preservation and Incorporation of Valuable Endoscopic Innovations) on real-time endoscopic assessment of the histology of diminutive colorectal polyps. Gastrointest Endosc. 2011;73(3):419-422.

45. Lieberman D, Moravec M, Holub J, Michaels L, Eisen G. Polyp size and advanced histology in patients undergoing colonoscopy screening: implications for CT colonography. Gastroenterology. 2008;135(4):1100-1105.

46. Ignjatovic A, East JE, Suzuki N, Vance M, Guenther T, Saunders BP. Optical diagnosis of small colorectal polyps at routine colonoscopy (Detect InSpect ChAracterise Resect and Discard; DISCARD trial): a prospective cohort study. Lancet Oncol. 2009;10(12):1171-1178. 
47. Hassan C, Pickhardt PJ, Rex DK. A resect and discard strategy would improve cost-effectiveness of colorectal cancer screening. Clin Gastroenterol Hepatol. 2010;8(10):865-869.

48. [No authors listed]. The Paris endoscopic classification of superficial neoplastic lesions: esophagus, stomach, and colon: November 30 to December 1, 2002. Gastrointest Endosc. 2003;58(Suppl 6): $\mathrm{S} 3-\mathrm{S} 43$.

49. Kudo SE, Lambert R, Allen JI, et al. Nonpolypoid neoplastic lesions of the colorectal mucosa. Gastrointest Endosc. 2008; 68(Suppl 4):S3-S47.

50. Kudo S, Hirota S, Nakajima T, et al. Colorectal tumours and pit pattern. J Clin Pathol. 1994;47(10):880-885.

51. McGill SK, Evangelou E, Ioannidis JPA, Soetikno RM, Kaltenbach T. Narrow band imaging to differentiate neoplastic and non-neoplastic colorectal polyps in real time: a meta-analysis of diagnostic operating characteristics. Gut. 2013;62(12):1704-1713.

52. Hayashi N, Tanaka S, Hewett DG, et al. Endoscopic prediction of deep submucosal invasive carcinoma: validation of the narrow-band imaging international colorectal endoscopic (NICE) classification. Gastrointest Endosc. 2013;78(4):625-632.

53. Matsuda T, Parra-Blanco A, Saito Y, Sakamoto T, Nakajima T. Assessment of likelihood of submucosal invasion in non-polypoid colorectal neoplasms. Gastrointest Endosc Clin N Am. 2010;20(3): 487-496

54. Gall TM, Markar SR, Jackson D, Haji A, Faiz O. Mini-probe ultrasonography for the staging of colon cancer: a systematic review and meta-analysis. Colorectal Dis. 2014;16(1):O1-O8.

55. Alves A, Panis Y, Mantion G, Slim K, Kwiatkowski F, Vicaut E. The AFC score: Validation of a 4-item predicting score of postoperative mortality after colorectal resection for cancer or diverticulitis - results of a prospective multicenter study in 1049 patients. Ann Surg. 2007;246(1):91-96.

56. Swan MP, Bourke MJ, Alexander S, Moss A, Williams SJ. Large refractory colonic polyps: is it time to change our practice? A prospective study of the clinical and economic impact of a tertiary referral colonic mucosal resection and polypectomy service. Gastrointest Endosc. 2009;70(6):1128-1136.

57. Moss A, Bourke MJ, Williams SJ, et al. Endoscopic mucosal resection outcomes and prediction of submucosal cancer from advanced colonic mucosal neoplasia. Gastroenterology. 2011;140(7):1909-1918.

58. Uraoka T, Saito Y, Matsuda T, et al. Endoscopic indications for endoscopic mucosal resection of laterally spreading tumours in the colorectum. Gut. 2006;55(11):1592-1597.

59. Mou S, Soetikno R, Shimoda T, Rouse R, Kaltenbach T. Pathologic predictive factors for lymph node metastasis in submucosal invasive (T1) colorectal cancer: a systematic review and meta-analysis. Surg Endosc. 2013;27(8):2692-2703.

60. Kitajima K, Fujimori T, Fujii S, et al. Correlations between lymph node metastasis and depth of submucosal invasion in submucosal invasive colorectal carcinoma: a Japanese collaborative study. J Gastroenterol. 2004;39(6):534-543.

61. Kobayashi N, Saito Y, Sano Y, et al. Determining the treatment strategy for colorectal neoplastic lesions: endoscopic assessment or the nonlifting sign for diagnosing invasion depth? Endoscopy. 2007;39(8): 701-705.

62. Longcroft-Wheaton G, Duku M, Mead R, Basford P, Bhandari P. Risk stratification system for evaluation of complex polyps can predict outcomes of endoscopic mucosal resection. Dis Colon Rectum. 2013;56(8):960-966

63. Kim MN, Kang JM, Yang JI, et al. Clinical features and prognosis of early colorectal cancer treated by endoscopic mucosal resection. J Gastroenterol Hepatol. 2011;26(11):1619-1625.

64. Park JJ, Cheon JH, Kwon JE, et al. Clinical outcomes and factors related to resectability and curability of EMR for early colorectal cancer. Gastrointest Endosc. 2011;74(6):1337-1346.

65. Buchner AM, Guarner-Argente C, Ginsberg GG. Outcomes of EMR of defiant colorectal lesions directed to an endoscopy referral center. Gastrointest Endosc. 2012;76(2):255-263.
66. Ferrara F, Luigiano C, Ghersi S, et al. Efficacy, safety and outcomes of 'inject and cut' endoscopic mucosal resection for large sessile and flat colorectal polyps. Digestion. 2010;82(4):213-220.

67. Luigiano C, Consolo P, Scaffidi MG, et al. Endoscopic mucosal resection for large and giant sessile and flat colorectal polyps: a single-center experience with long-term follow-up. Endoscopy. 2009;41(10):829-835.

68. Conio M, Repici A, Demarquay J-F, Blanchi S, Dumas R, Filiberti R. EMR of large sessile colorectal polyps. Gastrointest Endosc. 2004; 60(2):234-241.

69. Belle S, Haase L, Pilz LR, Post S, Ebert M, Kaehler G. Recurrence after endoscopic mucosal resection-therapy failure? Int J Colorectal Dis. 2014;29(2):209-215.

70. Brooker JC, Saunders BP, Shah SG, Thapar CJ, Suzuki N, Williams CB. Treatment with argon plasma coagulation reduces recurrence after piecemeal resection of large sessile colonic polyps: a randomized trial and recommendations. Gastrointest Endosc. 2002;55(3): 371-375.

71. Seitz U, Bohnacker S, Seewald S, Thonke F, Soehendra N. Long-term results of endoscopic removal of large colorectal adenomas. Endoscopy. 2003;35(8):S41-S44.

72. Repici A, Conio M, De Angelis C, et al. Insulated-tip knife endoscopic mucosal resection of large colorectal polyps unsuitable for standard polypectomy. Am J Gastroenterol. 2007;102(8):1617-1623.

73. Saito Y, Fukuzawa M, Matsuda T, et al. Clinical outcome of endoscopic submucosal dissection versus endoscopic mucosal resection of large colorectal tumors as determined by curative resection. Surg Endosc. 2010;24(2):343-352.

74. Tsiamoulos ZP, Bourikas LA, Saunders BP. Endoscopic mucosal ablation: a new argon plasma coagulation/injection technique to assist complete resection of recurrent, fibrotic colon polyps (with video). Gastrointest Endosc. 2012;75(2):400-404.

75. Inoue H, Kawano T, Tani M, Takeshita K, Iwai T. Endoscopic mucosal resection using a cap: techniques for use and preventing perforation. Can J Gastroenterol. 1999;13(6):477-480.

76. Ono A, Fujii T, Saito Y, et al. Endoscopic submucosal resection of rectal carcinoid tumors with a ligation device. Gastrointest Endosc. 2003;57(4):583-587.

77. Binmoeller KF, Weilert F, Shah J, Bhat Y, Kane S. "Underwater" EMR without submucosal injection for large sessile colorectal polyps (with video). Gastrointest Endosc. 2012;75(5):1086-1091.

78. Wang AY, Flynn MM, Patrie JT, et al. Underwater endoscopic mucosal resection of colorectal neoplasia is easily learned, efficacious, and safe. Surg Endosc. 2014;28(4):1348-1354.

79. Cao Y, Liao C, Tan A, Gao Y, Mo Z, Gao F. Meta-analysis of endoscopic submucosal dissection versus endoscopic mucosal resection for tumors of the gastrointestinal tract. Endoscopy. 2009;41(9):751-757.

80. Saito Y, Uraoka T, Yamaguchi Y, et al. A prospective, multicenter study of 1111 colorectal endoscopic submucosal dissections (with video). Gastrointest Endosc. 2010;72(6):1217-1225.

81. Tanaka S, Terasaki M, Kanao H, Oka S, Chayama K. Current status and future perspectives of endoscopic submucosal dissection for colorectal tumors. Dig Endosc. 2012;24 Suppl 1:73-79.

82. Tanaka S, Oka S, Kaneko I, et al. Endoscopic submucosal dissection for colorectal neoplasia: possibility of standardization. Gastrointest Endosc. 2007;66(1):100-107.

83. Nakadoi K, Tanaka S, Hayashi N, et al. Clinical outcomes of endoscopic submucosal dissection for rectal tumor close to the dentate line. Gastrointest Endosc. 2012;76(2):444-450.

84. Khawaja FI. Colonoscopic removal of an appendiceal polyp. Saudi J Gastroenterol. 2002;8(3):93-95.

85. Agrawal D, Chak A, Champagne BJ, Marks JM, Delaney CP. Endoscopic mucosal resection with full-thickness closure for difficult polyps: a prospective clinical trial. Gastrointest Endosc. 2010;71(6): 1082-1088.

86. Wilhelm D, von Delius S, Weber L, et al. Combined laparoscopicendoscopic resections of colorectal polyps: 10-year experience and follow-up. Surg Endosc. 2009;23(4):688-693. 
87. Fukunaga Y, Tamegai Y, Chino A, et al. New technique of en bloc resection of colorectal tumor using laparoscopy and endoscopy cooperatively (laparoscopy and endoscopy cooperative surgery - colorectal). Dis Colon Rectum. 2014;57(2): 267-271.

88. Takizawa K, Knipschield MA, Gostout CJ. Submucosal endoscopy with mucosal resection (SEMR): a new hybrid technique of endoscopic submucosal balloon dissection in the porcine rectosigmoid colon. Surg Endosc. 2013;27(12):4457-4462.

89. Brigic A, Symons NR, Faiz O, Fraser C, Clark SK, Kennedy RH. A systematic review regarding the feasibility and safety of endoscopic full thickness resection (EFTR) for colonic lesions. Surg Endosc. 2013;27(10):3520-3529.

90. Ko CW, Dominitz JA. Complications of colonoscopy: magnitude and management. Gastrointest Endosc Clin N Am. 2010;20(4): 659-671.

91. Ko CW, Riffle S, Michaels L, et al. Serious complications within 30 days of screening and surveillance colonoscopy are uncommon. Clin Gastroenterol Hepatol. 2010;8(2):166-173.

92. Panteris V, Haringsma J, Kuipers EJ. Colonoscopy perforation rate, mechanisms and outcome: from diagnostic to therapeutic colonoscopy. Endoscopy. 2009;41(11):941-951.

93. Rabeneck L, Paszat LF, Hilsden RJ, et al. Bleeding and perforation after outpatient colonoscopy and their risk factors in usual clinical practice. Gastroenterology. 2008;135(6):1899-1906.

94. Norton ID, Wang L, Levine SA, et al. Efficacy of colonic submucosal saline solution injection for the reduction of iatrogenic thermal injury. Gastrointest Endosc. 2002;56(1):95-99.

95. Hui AJ, Wong RM, Ching JY, Hung LC, Chung SC, Sung JJ. Risk of colonoscopic polypectomy bleeding with anticoagulants and antiplatelet agents: analysis of 1657 cases. Gastrointest Endosc. 2004;59(1):44-48.

96. Heldwein W, Dollhopf M, Rosch T, et al. The Munich Polypectomy Study (MUPS): prospective analysis of complications and risk factors in 4000 colonic snare polypectomies. Endoscopy. 2005;37(11): $1116-1122$.

97. Watabe H, Yamaji Y, Okamoto M, et al. Risk assessment for delayed hemorrhagic complication of colonic polypectomy: polyp-related factors and patient-related factors. Gastrointest Endosc. 2006;64(1):73-78.

98. Buddingh KT, Herngreen T, Haringsma J, et al. Location in the right hemi-colon is an independent risk factor for delayed post-polypectomy hemorrhage: a multi-center case-control study. Am J Gastroenterol. 2011;106(6):1119-1124.

99. Sawhney MS, Salfiti N, Nelson DB, Lederle FA, Bond JH. Risk factors for severe delayed postpolypectomy bleeding. Endoscopy. 2008;40(2):115-119.

100. Shioji K, Suzuki Y, Kobayashi M, et al. Prophylactic clip application does not decrease delayed bleeding after colonoscopic polypectomy. Gastrointest Endosc. 2003;57(5):691-694.

101. Lee CK, Lee SH, Park JY, et al. Prophylactic argon plasma coagulation ablation does not decrease delayed postpolypectomy bleeding. Gastrointest Endosc. 2009;70(2):353-361.

102. ASGE Standards of Practice Committee; Anderson MA, Ben-Menachem T, Gan SI, et al. Management of antithrombotic agents for endoscopic procedures. Gastrointest Endosc. 2009;70(6): 1060-1070.

Clinical and Experimental Gastroenterology

\section{Publish your work in this journal}

Clinical and Experimental Gastroenterology is an international, peerreviewed, open access journal, publishing all aspects of gastroenterology in the clinic and laboratory, including: Pathology, pathophysiology of gastrointestinal disease; Investigation and treatment of gastointestinal disease; Pharmacology of drugs used in the alimentary tract;
103. Singh M, Mehta N, Murthy UK, Kaul V, Arif A, Newman N. Postpolypectomy bleeding in patients undergoing colonoscopy on uninterrupted clopidogrel therapy. Gastrointest Endosc. 2010;71(6): 998-1005.

104. Witt DM, Delate T, McCool KH, et al. Incidence and predictors of bleeding or thrombosis after polypectomy in patients receiving and not receiving anticoagulation therapy. J Thromb Haemost. 2009;7(12):1982-1989.

105. Metz AJ, Bourke MJ, Moss A, Williams SJ, Swan MP, Byth K. Factors that predict bleeding following endoscopic mucosal resection of large colonic lesions. Endoscopy. 2011;43(6):506-511.

106. Liaquat H, Rohn E, Rex DK. Prophylactic clip closure reduced the risk of delayed postpolypectomy hemorrhage: experience in 277 clipped large sessile or flat colorectal lesions and 247 control lesions. Gastrointest Endosc. 2013;77(3):401-407.

107. Hogan RB, Hogan RB 3rd. Epinephrine volume reduction of giant colon polyps facilitates endoscopic assessment and removal. Gastrointest Endosc. 2007;66(5):1018-1022.

108. Kouklakis G, MpoumponarisA, GatopoulouA,EfraimidouE, Manolas K, Lirantzopoulos N. Endoscopic resection of large pedunculated colonic polyps and risk of postpolypectomy bleeding with adrenaline injection versus endoloop and hemoclip: a prospective, randomized study. Surg Endosc. 2009;23(12):2732-2737.

109. Dobrowolski S, Dobosz M, Babicki A, Dymecki D, Hac S. Prophylactic submucosal saline-adrenaline injection in colonoscopic polypectomy: prospective randomized study. Surg Endosc. 2004;18(6):990-993.

110. Weston AP, Campbell DR. Diminutive colonic polyps: histopathology, spatial distribution, concomitant significant lesions, and treatment complications. Am J Gastroenterol. 1995;90(1):24-28.

111. Fujishiro M, Yahagi N, Kakushima N, et al. Outcomes of endoscopic submucosal dissection for colorectal epithelial neoplasms in 200 consecutive cases. Clin Gastroenterol Hepatol. 2007;5(6):678-683.

112. Tamegai Y, Saito Y, Masaki N, et al. Endoscopic submucosal dissection: a safe technique for colorectal tumors. Endoscopy. 2007;39(5):418-422.

113. Toyonaga T, Man-i M, Fujita T, et al. Retrospective study of technical aspects and complications of endoscopic submucosal dissection for laterally spreading tumors of the colorectum. Endoscopy. 2010;42(9):714-722.

114. Nishiyama N, Mori H, Kobara H, et al. Efficacy and safety of overthe-scope clip: including complications after endoscopic submucosal dissection. World J Gastroenterol. 2013;19(18):2752-2760.

115. Kantsevoy SV, Bitner M, Mitrakov AA, Thuluvath PJ. Endoscopic suturing closure of large mucosal defects after endoscopic submucosal dissection is technically feasible, fast, and eliminates the need for hospitalization (with videos). Gastrointest Endosc. 2014;79(3): 503-507.

116. Cha JM, Lim KS, Lee SH, et al. Clinical outcomes and risk factors of post-polypectomy coagulation syndrome: a multicenter, retrospective, case-control study. Endoscopy. 2013;45(3):202-207.

117. Leggett CL, Gorospe EC, Lutzke L, Anderson M, Wang KK. A new era: endoscopic tissue transplantation. Curr Opin Gastroenterol. 2013;29(5):495-500.

118. Hassan C, Quintero E, Dumonceau JM, et al. Post-polypectomy colonoscopy surveillance: European Society of Gastrointestinal Endoscopy (ESGE) Guideline. Endoscopy. 2013;45(10):842-851.

119. Lieberman DA, Rex DK, Winawer SJ, Giardiello FM, Johnson DA, Levin TR. Guidelines for colonoscopy surveillance after screening and polypectomy: a consensus update by the US Multi-Society Task Force on Colorectal Cancer. Gastroenterology. 2012;143(3):844-857.

\section{Dovepress}

Immunology/genetics/genomics related to gastrointestinal disease. This journal is indexed on CAS. The manuscript management system is completely online and includes a very quick and fair peer-review system. Visit http://www.dovepress.com/testimonials.php to read real quotes from published authors. 